\title{
Estudo sobre Valores em Adolescentes
}

\author{
Priscilla Brandi Gomes Godoy \\ Nancy Ramacciotti Oliveira-Monteiro \\ Universidade Federal de São Paulo \\ São Paulo, SP, Brasil
}

\begin{abstract}
RESUMO
Os valores humanos podem ser associados ao desenvolvimento positivo de indivíduos e muitas vezes são utilizados como explicação para comportamentos e suas motivações. Com base na Teoria Funcionalista dos Valores Humanos, de Gouveia, este estudo objetivou investigar valores humanos em adolescentes, a partir de seis subfunções valorativas (existência, realização, normativa, suprapessoal, experimentação e interativa). Com uso do Questionário dos Valores Básicos, de Gouveia, Milfont, Fischer e Santos (2008), foram avaliados 453 estudantes do ensino fundamental II e médio, ambos os sexos, idades na média de 14,9 anos, em seis escolas da Baixada Santista (SP). As análises descritiva e inferencial indicaram resultados com predomínio da subfunção existência na amostra geral, com diferenças significativas para maiores médias em meninas e em escolas públicas. Os valores da subfunção existência têm sido relacionados a comportamentos positivos no âmbito social e podem ser considerados como reflexo do ensinado e vivenciado na escola, família e sociedade.
\end{abstract}

Palavras-chave: Moral; Adolescência; Escola; Diferenças Sexuais.

\section{ABSTRACT}

\section{Study of Values in Adolescents}

Human values can be associated with a positive development of individuals and often used as an explanation for their behavior and motivation. Based on Functionalist Theory of Human Values, of Gouveia, this study aimed to investigate human values in adolescents from six values sub-functions (existence, promotion, normative, suprapersonal, excitement and interactive). Using the Basic Values Questionnaire, of Gouveia, Milfont, Fischer and Santos (2008), were evaluated 453 elementary and high school students, with the average age of 14.9 years old and of both sexes, of six schools of Santos (SP). The descriptive and inferential analyzes indicated results with predominance of value sub-function existence in the whole sample, with significant differences for higher averages in girls and in public schools. The values of the sub-function existence have been linked to positive behaviors in social context and can be considered a reflection of what is taught and experienced in school, family and society.

Keywords: Morality; Adolescence; School; Human Sex Differences.

\section{RESUMEN}

\section{Estudio de los Valores en los Adolescentes}

Los valores humanos se pueden asociar a un desarrollo positivo de las personas y, a menudo utilizados como una explicación de su comportamiento y la motivación. Basado en Teoría Funcionalista de los Valores Humanos, de Gouveia, este estudio tuvo como objetivo investigar los valores humanos en los adolescentes desde seis subfunciones evaluativos (existencia, realización, normativa, suprapersonal, experimentación y interactiva). Utilizando el Cuestionario de Valores Básicos, de Gouveia, Milfont, Fischer y Santos (2008), se evaluaron 453 estudiantes de la escuela elemental y media, con la edad media de 14,9 años y de ambos sexos, de seis escuelas de Santos (SP). Las análisis descriptiva e inferencial indican la predominancia de la subfunción existencia en toda la muestra, con diferencias significativas para las medias más altas en las niñas y en las escuelas públicas. Los valores de la subfunción existencia se han relacionado con comportamientos positivos en el contexto social y pueden considerarse un reflejo de lo que se enseña y con experiencia en la escuela, la familia y la sociedad.

Palabras clave: Moral; Adolescencia; Escuela; Diferencias Sexuales. 


\section{INTRODUÇÃO}

A temática de valores humanos tem sido inserida nos estudos da moralidade humana, que no âmbito da literatura psicológica é expressivamente estudada através da perspectiva psicológica cognitiva (Bataglia, Morais, \& Lepre, 2010; Souza \& Vasconcelos, 2009; Razera, 2009). Estudos pioneiros de Piaget e Kohlberg mostram o desenvolvimento da moral em associação com a capacidade cognitiva individual de ser empático com os outros, de descentralização de si mesmo, e de percepção de demandas ambientais (Carlo \& Koller, 1998). Por ditames da teoria construtivista de Piaget, ambientes democráticos e cooperativos são importantes para a construção do caráter moral desde a infância, favorecendo o desenvolvimento da autonomia, tanto moral quanto intelectual. Tais ambientes são aqueles em que há estímulos para a cooperação, o respeito mútuo e a reciprocidade entre indivíduos da mesma idade, e também a presença de respeito por parte de adultos frente a possibilidade de participação das crianças nos processos de tomada de decisão. A escola pode constituir-se, em maior ou menor grau, como um ambiente com essa qualidade, a partir de condições necessárias para o estabelecimento de relações com níveis reduzidos de autoridade/prestígios entre alunos e professores (Araújo, 2001).

Por outro lado, os pressupostos das teorias do desenvolvimento da moral, de Piaget e Kohlberg, assim como a vertente teórica da moral pró-social, têm sido alvos de debates. As críticas, de certo modo, apontam para a necessidade de uma compreensão mais complexa das variáveis culturais presentes e de uma atribuição de valores humanos no campo dos comportamentos e pensamentos (Vasconcelos, Arantes, Souza, Trevisol \& Belloto, 2010).

A condição de diversidade dos valores humanos é muitas vezes utilizada na tentativa de explicação para atitudes e comportamentos dos sujeitos na sociedade, numa ampla gama de domínios, como posturas religiosas, preconceitos, consumo de drogas, e comportamentos antissociais e pró-sociais (Medeiros, 2011).

Quando tratamos da temática de valores no sentido psicológico, aspectos sociais, culturais e históricos devem ser salientados. Hernandez, Arango e Quintana (2012) sintetizam essa riqueza de dimensões ao afirmar que os valores humanos são adquiridos e se formam como resultado da realidade em que cada sujeito vive. Nesse sentido, a escola e a família terão papel preponderante na aquisição dos valores por parte de crianças e adolescentes, e à medida que ensinam normas e padrões, expressam o conjunto de valores presentes na sociedade, reproduzindo os valores de gerações presentes e passadas.
A adolescência é considerada um período de experimentação de valores, papéis sociais e identidades que poderão permanecer na vida adulta (Salles, 2005), além de um período crítico na vida de cada indivíduo, em que ele vivencia descobertas significativas e afirma sua personalidade e individualidade (Cavalcante, Alves, \& Barroso, 2008). Apesar da Organização Mundial da Saúde definir adolescentes como pessoas de 10 a 19 anos, é possível considerar que a adolescência começa na biologia e termina na cultura, ou seja, em algumas sociedades, essa etapa do ciclo evolutivo pode ser breve, enquanto que em outras (evidenciadas como tecnologicamente mais desenvolvidas), tende a se prolongar (Traverso-Yépez \& Pinheiro, 2002). Além das mudanças biológicas verificadas nesse período da vida do ser humano, há avanços em todo o seu processo maturativo biopsicossocial, ocorrendo mudanças de papéis, de ideias e de atitudes (Pratta \& Santos, 2007).

Não é incomum que temas referentes a 'crises de valores' sejam associados à sociedade contemporânea, pelo menos em termos de sociedades urbanas do mundo ocidental. Para La Taille e Menin (2009) o que ocorre, na verdade, seria uma situação de 'valores em crise', o que traz um significado de 'valores em processo de transformação'. Para esses autores, a 'crise de valores', de outra maneira, parece remeter a um processo de quase extinção e ausência de valores, e não à sua transformação. Em diferentes épocas históricas surgem perturbações relativas à falta ou à inversão de valores na sociedade, geradores de um mal-estar moral, como podemos ver também em Freud (2010). Os valores morais de uma sociedade podem ser substituídos por outros valores morais, mas podem também ser substituídos por valores contrários à ética, como em casos mais extremos de radicalismos políticos.

Nos precursores estudos de Rokeach (1981), os valores humanos individuais são tidos como estados finais desejados pelas pessoas, definidos em sua importância, e através dos quais elas avaliam suas experiências. Com base nessa proposta, Schwartz (2005) apresenta uma teoria que enfatiza o papel dos valores humanos como indicadores das motivações, definindoos como critérios ou metas que, transcendendo situações específicas, guiam os comportamentos e as atitudes das pessoas, de uma forma ordenada e hierárquica, a partir de seu grau de importância.

Numa proposta de avanço explicativo e investigativo sobre valores humanos, Gouveia elabora em 1998 a Teoria Funcionalista dos Valores Humanos a partir de algumas críticas aos modelos até então existentes sobre a temática, contudo ainda considerando alguns aspectos dos mesmos (Gouveia, 2013). Desde então, essa teoria vem sendo utilizada em diversos trabalhos brasileiros 
para verificação de sua adequação, principalmente no contexto paraibano, e para avaliação da correlação de valores com diferentes aspectos da vida (Formiga \& Gouveia, 2005; Medeiros et al., 2012; Gouveia, Meira, Gusmão, Souza Filho, \& Souza, 2008; Gouveia et al., 2010; Milfont, Gouveia, \& Costa, 2006).

Segundo a Teoria Funcionalista dos Valores Humanos (Gouveia, 2013), os valores têm como função dirigir comportamentos (em termos de sua orientação) e também expressar cognitivamente as necessidades humanas (em termos de motivações). A função dos valores de guiar comportamentos é sistematizada por critérios de orientação divididos em: pessoais, sociais e centrais; e a função de expressar necessidades considera os valores humanos como representação de necessidades idealistas e materialistas. A partir dessas duas dimensões funcionais de valores, derivam-se seis subfunções valorativas, tais quais: experimentação, realização, existência, suprapessoal, interativa e normativa. Gouveia, Milfont, Fischer e Santos (2008) propõem três valores como representantes de cada subfunção valorativa, porém não limitam a diversidade axiológica a eles, podendo haver em outras culturas ou contextos, outros valores que se enquadrem no esquema da teoria. A Figura 1 ilustra o esquema conceitual da Teoria Funcionalista dos Valores Humanos a partir das funções e subfunções dos valores, assim como os valores humanos correspondentes propostos por Gouveia, Milfont, Fischer e Santos (2008).

Ainda com respeito a essa teoria, as subfunções valorativas são descritas por Gouveia (2013) da forma colocada a seguir. A subfunção existência (orientação central e necessidades materialistas) representa necessidades fisiológicas básicas e de segurança, e os indivíduos guiados por ela têm como propósito garantir condições básicas para a sobrevivência biológica e psicológica. A subfunção realização (orientação pessoal e necessidades materialistas) representa necessidades de autoestima e guia indivíduos que visam a autopromoção. A subfunção normativa (orientação social e necessidades materialistas) expressa necessidade de controle e dirige comportamentos de obediência a autoridades e de preservação de normas de uma cultura. Por sua vez, a subfunção suprapessoal (orientação central e necessidades idealista) expressa necessidades de estética e cognição e guia comportamentos maduros e de autorrealização. Já a subfunção experimentação (orientação pessoal e necessidades idealistas) representa necessidade de satisfação e prazer, guiando comportamento de inconformidade com regras sociais. Finalmente, a subfunção interativa (orientação social e necessidades idealistas) expressa necessidades de pertença a grupos e guia indivíduos que priorizam estabelecer e manter relações interpessoais.

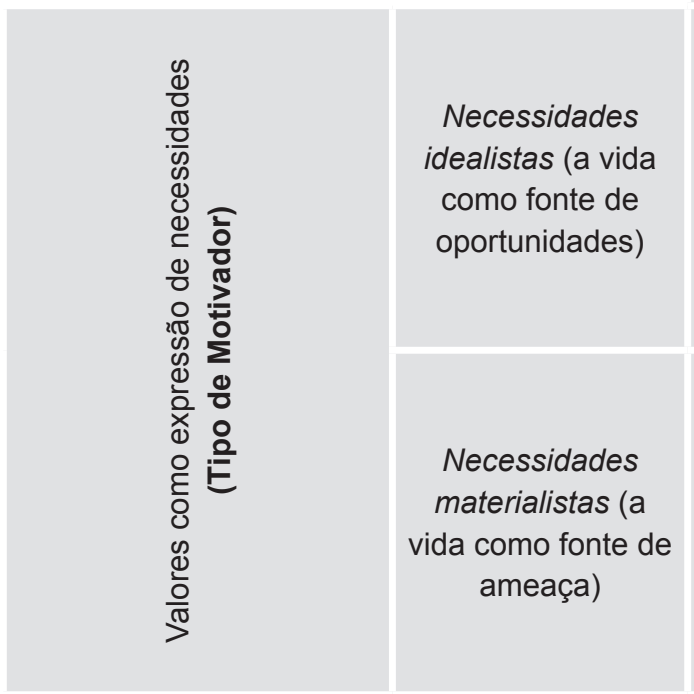

\begin{tabular}{|c|c|c|}
\hline \multicolumn{3}{|c|}{$\begin{array}{l}\text { Valores como padrão-guia de comportamentos } \\
\text { (Tipo de orientação) }\end{array}$} \\
\hline $\begin{array}{c}\text { Metas Pessoais } \\
\text { (o indivíduo por si } \\
\text { mesmo) }\end{array}$ & $\begin{array}{c}\text { Metas Centrais } \\
\text { (o propósito geral } \\
\text { da vida) }\end{array}$ & $\begin{array}{c}\text { Metas sociais } \\
\text { (o indivíduo na } \\
\text { comunidade) }\end{array}$ \\
\hline $\begin{array}{c}\text { Experimentação } \\
\text { Emoção } \\
\text { Prazer } \\
\text { Sexualidade }\end{array}$ & $\begin{array}{c}\text { Suprapessoal } \\
\text { Beleza } \\
\text { Conhecimento } \\
\text { Maturidade }\end{array}$ & $\begin{array}{l}\text { Interativa } \\
\text { Afetividade } \\
\text { Apoio Social } \\
\text { Convivência }\end{array}$ \\
\hline $\begin{array}{c}\text { Realização } \\
\text { Exxito } \\
\text { Poder } \\
\text { Prestígio }\end{array}$ & $\begin{array}{l}\text { Existência } \\
\text { Estabilidade } \\
\text { Saúde } \\
\text { Sobrevivência }\end{array}$ & $\begin{array}{c}\text { Normativa } \\
\text { Obediência } \\
\text { Religiosidade } \\
\text { Tradição }\end{array}$ \\
\hline
\end{tabular}

Figura 1. Funções, subfunções e valores específicos (Gouveia, 2013, p.132) 
A Teoria Funcionalista dos Valores Humanos relaciona-se com a psicologia positiva, uma vertente da psicologia que investiga fenômenos vinculados ao lado 'bom' das pessoas, como emoções, características e intenções positivas. Segundo a teoria de Gouveia (2013), o homem é naturalmente bom e orientado por aspectos positivos da vida, sendo os valores humanos atributos sempre positivos. Apesar disso, comportamentos aversivos, por exemplo, teriam sua origem em um predomínio excessivo por parte de algumas pessoas de certos valores em detrimento de outros.

Nessa perspectiva, determinados tipos de valores podem determinar certos tipos de comportamentos, de forma que investir em valores que visam o individualismo, por exemplo, pode resultar em uma maior frequência de manifestações comportamentais negativas entre os jovens. Por outro lado, valores que estimulam comportamentos mais coletivistas podem contribuir com uma diminuição de condutas antissociais e delitivas. Também se deve destacar que, no caso de adolescentes, são esperados valores da subfunção valorativa experimentação, já que a adolescência é uma etapa do desenvolvimento na qual se fazem presentes novas explorações e também questionamentos frente ao estabelecido, condições comuns no processo de construção da identidade.

Uma busca nas plataformas BVS (Biblioteca Virtual em Saúde), DEDALUS (Banco de Dados Bibliográficos da Universidade de São Paulo), LILACS (Literatura Latino-Americana e do Caribe de Ciências da Saúde), e SciELO (Scientific Electronic Library Online) por artigos de pesquisas empíricas brasileiras datados de 2009 a 2014 sobre a temática de 'valores' e 'valores humanos' exibiu estudos baseados em diferentes instrumentos e referenciais teóricos. Dentre os artigos encontrados, dois trataram a temática de "Valores e adolescência/juventude", a partir de um mapeamento de valores em populações jovens (Macedo \& Kublikowski, 2009; Santos, Yonekura, Soares \& Campos, 2012).

Com uso do "Proflies of Student Life: Attitudes and Behaviors", Macedo e Kublikowski (2009) investigaram aspectos de desenvolvimento positivo de adolescentes com baixa, média e alta vulnerabilidade, da cidade de São Paulo (SP), na busca do mapeamento de seus valores. O estudo indicou valores positivos (igualdade e justiça social, honestidade, integridade, responsabilidade e cuidado) na maioria da população investigada. Já o estudo de Santos, Yonekura, Soares \& Campos (2012) tratou de posicionamentos de jovens estudantes em relação às expressões de valores sociais contemporâneos, verificados a partir de um debate entre jovens de 15 e 24 anos da cidade de Santo André
(SP) sobre um conjunto de 73 expressões valorativas que diziam respeito à realização/sucesso; segurança, confiança e futuro; drogas e outras formas de bemestar e prazer. Os resultados indicaram que a maioria dos jovens investigados concordou que a 'educação garante o futuro', que 'pais não têm direito de bater nos filhos', que 'ter os pais como exemplo é importante', que 'usar camisinha é importante', e que 'a maconha não deveria ser legalizada'.

Ainda na busca por estudos com a temática de 'valores' e 'valores humanos' foi encontrado o trabalho de Oliveira e Saldanha (2010) que investigou valores e perspectivas de futuro em estudantes de escolas públicas e privadas. Os autores verificaram que a maioria da amostra (91\%), de ambos os tipos de escola, indicou perspectivas de futuro positivas, incluindo conclusão do ensino médio, ter casa própria, vida familiar feliz, e emprego que trouxesse qualidade de vida e respeito da comunidade. A maioria dos investigados que apresentaram perspectivas negativas de futuro era de estudantes de escola pública.

A partir dessas colocações, e com escolha da circunscrição teórica de Gouveia (2013), apresentase um estudo que objetivou avaliar valores em jovens, verificando possíveis diferenças dessa avaliação quanto ao sexo e à inserção em escolas privadas ou públicas.

\section{MÉTODO}

\section{Participantes}

Participaram do estudo 453 estudantes do ensino fundamental II e do ensino médio, com idades entre 13 e 19 anos (média 14,9 anos) e de ambos os sexos, de seis escolas de uma cidade de médio porte, da região metropolitana da Baixada Santista (SP). As escolas públicas foram indicadas pela Secretaria de Educação do município, e as privadas foram selecionadas por conveniência e disponibilidade das mesmas.

Para caracterização da amostra foi usado o Critério de Classificação Econômica Brasil (CCEB) (ABEP, 2013), um questionário que avalia classes econômicas (A1, A2, B1, B2, C1, C2, D e E) a partir de bens de consumo e do grau de instrução do chefe da família. Nesta caracterização da amostra, as classes do CCEB foram agrupadas em A/B e C/D/E, faixas de classes econômicas mais altas e mais baixas, respectivamente. A Tabela 1 apresenta dados relativos à caracterização da amostra.

\section{Materiais e Procedimento}

A coleta de dados foi feita de forma coletiva em salas de aulas das escolas estudadas, com uso do 
TABELA 1

Medidas Descritivas de Caracterização da Amostra

\begin{tabular}{|c|c|c|c|c|c|c|c|}
\hline \multirow{3}{*}{ Sexo } & \multirow{3}{*}{$\begin{array}{c}\text { Classe } \\
\text { econômica }\end{array}$} & \multicolumn{6}{|c|}{ Escolaridade } \\
\hline & & \multicolumn{2}{|c|}{ Fundamental II } & \multicolumn{2}{|c|}{ Médio } & \multicolumn{2}{|c|}{ Total } \\
\hline & & Públicas & Privadas & Públicas & Privadas & Públicas & Privadas \\
\hline \multirow{3}{*}{ Feminino } & $\mathrm{A} / \mathrm{B}$ & $24(5,29 \%)$ & $56(12,36 \%)$ & $42(9,27 \%)$ & $60(13,24 \%)$ & $66(14,56 \%)$ & $116(25,60 \%)$ \\
\hline & $\mathrm{C} / \mathrm{D} / \mathrm{E}$ & $39(8,60 \%)$ & $3(0,66 \%)$ & $19(4,19 \%)$ & $3(0,66 \%)$ & $58(12,80 \%)$ & $6(1,32 \%)$ \\
\hline & Total & $63(13,90 \%)$ & $59(13,02 \%)$ & $61(13,46 \%)$ & $63(13,46 \%)$ & $124(27,37 \%)$ & $122(26,93 \%)$ \\
\hline \multirow{3}{*}{ Masculino } & $\mathrm{A} / \mathrm{B}$ & $25(5,51 \%)$ & $58(12,80 \%)$ & $32(7,06 \%)$ & $48(10,59 \%)$ & $57(12,58 \%)$ & $106(23,39 \%)$ \\
\hline & $\mathrm{C} / \mathrm{D} / \mathrm{E}$ & $22(4,85 \%)$ & $8(1,76 \%)$ & $9(1,98 \%)$ & $5(1,10 \%)$ & $31(6,84 \%)$ & $13(2,86 \%)$ \\
\hline & Total & $47(10,37 \%)$ & $66(14,56 \%)$ & $41(9,05 \%)$ & $53(11,69 \%)$ & $88(19,42 \%)$ & $119(26,26 \%)$ \\
\hline \multirow{3}{*}{ Total } & $\mathrm{A} / \mathrm{B}$ & $49(10,81 \%)$ & $114(25,16 \%)$ & $74(16,33 \%)$ & $108(23,84 \%)$ & $123(27,15 \%)$ & $222(49 \%)$ \\
\hline & $\mathrm{C} / \mathrm{D} / \mathrm{E}$ & $61(13,48 \%)$ & $11(2,42 \%)$ & $28(6,18 \%)$ & $8(1,76 \%)$ & $89(19,64 \%)$ & $19(4,19 \%)$ \\
\hline & Total & $110(24,28 \%)$ & $125(27,59 \%)$ & $102(22,51 \%)$ & $116(25,60 \%)$ & $212(46,79 \%)$ & $241(53,20 \%)$ \\
\hline
\end{tabular}

Questionário dos Valores Básicos (QVB), instrumento validado para a população brasileira por Gouveia, Milfont, Fischer e Santos (2008). O QVB é uma versão revisada formada por 18 itens do instrumento proposto por Gouveia (2003), inicialmente com 24 itens, para testar a tipologia dos valores básicos. O questionário propõe a avaliação de seis funções psicossociais a partir de três valores para cada função. Cada item do instrumento corresponde a um valor humano e as pessoas devem avaliar o grau de importância de cada valor como um princípio guia na sua vida. O QVB utiliza uma escala de sete pontos, variando de 1 (nada importante) a 7 (muito importante). Os valores presentes no questionário são: apoio social, êxito, sexualidade, conhecimento, emoção, poder, afetividade, religiosidade, saúde, prazer, prestígio, obediência, estabilidade pessoal, convivência, beleza, tradição, sobrevivência e maturidade.

Foram guardados os devidos cuidados de procedimentos éticos para a realização da pesquisa. $\mathrm{O}$ levantamento dos dados foi realizado nas salas de aula das escolas, que foram selecionadas pelo critério de acessibilidade.

Os dados foram tratados de formas descritiva e inferencial. Para cada sujeito foi calculada a média dos graus da escala Likert dos itens do QVB. Esses dados foram analisados por meio de uma análise de variância (ANOVA) de três fatores: subfunções, sexo e inserção em escola pública ou privada. O nível de significância foi considerado como $\alpha=0,005$.

\section{RESULTADOS}

A subfunção valorativa existência (média 6,12 e desvio padrão 0,74 ), destacou-se como predominante na amostra geral, seguida da subfunção suprapessoal (média 5,73 e desvio padrão 0,86 ), como pode ser observado na Tabela 2.

Não foi possível estabelecer um padrão geral entre as variáveis visto a forte interação observada entre subfunções valorativas e tipo de escola $(\mathrm{F}=119.035$, $\mathrm{p}<0.001)$, e subfunções valorativas e sexo $(\mathrm{F}=57.783$, $\mathrm{p}<0.001$ ), conforme dados ilustrados na Tabela 3.

Por este motivo foram realizados testes ANOVA de dois fatores para cada tipo de subfunção valorativa, de forma a verificar os efeitos do tipo de escola, e de sexo. Nesses testes ANOVA de dois fatores não foram observadas interações significativas entre sexo e tipo de escola, como apresentado na Tabela 4. Resultados para efeitos principais, dessa maneira, puderam ser interpretados.

Conforme dados das Tabelas 2 e 4, as escolas públicas obtiveram médias estatisticamente mais elevadas para as subfunções existência (privada $=5,97$, pública $=6,29$ ), normativa (privada $=4,88$, públi$\mathrm{ca}=5,59)$, realização $($ privada $=4,94$, pública $=5,13) \mathrm{e}$ suprapessoal (privada $=5,97$, pública $=6,29$ ), enquanto as escolas privadas, somente obtiveram médias estatisticamente significativas para experimentação ( rivada $=5,28$, pública $=5,09$ ). Não houve diferença significativa entre escolas para a função valorativa interativa (privada $=5,48$, pública $=5,56$ ). 
Também, de acordo com dados expostos nas Tabelas 2 e 4, as meninas apresentaram maiores médias significativas para as subfunções valorativas interativa (homem $=5,36$, mulher $=5,65)$, normativa (homem $=5,06$, mulher $=5,34)$ e suprapessoal (homem $=5,55$, mulher $=5,88$ ). Os meninos, por sua vez, obtiveram maiores médias significativas para a subfunção valorativa experimentação (homem= $5,30$, mulher $=5,10)$. Não houve diferenças significativas entre sexo para as funções valorativas existência $($ homem $=6,07$, mulher $=6,17)$ e realização (homem $=5,08$, mulher $=4,99$ ).

\section{TABELA 2}

Valores médios e desvio padrão para cada Subfunção por tipo de escola e sexo

\begin{tabular}{|c|c|c|c|c|}
\hline Subfunção & Escola & Sexo & Média & $\begin{array}{l}\text { Desvio } \\
\text { padrão }\end{array}$ \\
\hline \multirow{4}{*}{ Existência } & \multirow{2}{*}{ Privada } & Homem & 5,96 & 0,87 \\
\hline & & Mulher & 5,99 & 0,71 \\
\hline & \multirow{2}{*}{ Pública } & Homem & 6,22 & 0,69 \\
\hline & & Mulher & 6,35 & 0,62 \\
\hline \multirow{4}{*}{ Experimentação } & \multirow{2}{*}{ Privada } & Homem & 5,32 & 1,01 \\
\hline & & Mulher & 5,24 & 1,03 \\
\hline & \multirow{2}{*}{ Pública } & Homem & 5,27 & 1,03 \\
\hline & & Mulher & 4,96 & 0,93 \\
\hline \multirow{4}{*}{ Interativa } & \multirow{2}{*}{ Privada } & Homem & 5,30 & 1,13 \\
\hline & & Mulher & 5,66 & 0,84 \\
\hline & \multirow{2}{*}{ Pública } & Homem & 5,45 & 0,81 \\
\hline & & Mulher & 5,65 & 0,85 \\
\hline \multirow{4}{*}{ Normativa } & \multirow{2}{*}{ Privada } & Homem & 4,75 & 1,18 \\
\hline & & Mulher & 5,00 & 1,02 \\
\hline & \multirow{2}{*}{ Pública } & Homem & 5,48 & 1,06 \\
\hline & & Mulher & 5,67 & 0,99 \\
\hline \multirow{4}{*}{ Realização } & \multirow{2}{*}{ Privada } & Homem & 5,05 & 1,06 \\
\hline & & Mulher & 4,84 & 0,88 \\
\hline & \multirow{2}{*}{ Pública } & Homem & 5,12 & 0,93 \\
\hline & & Mulher & 5,14 & 0,84 \\
\hline \multirow{4}{*}{ Suprapessoal } & \multirow{2}{*}{ Privada } & Homem & 5,52 & 0,92 \\
\hline & & Mulher & 5,81 & 0,87 \\
\hline & \multirow{2}{*}{ Pública } & Homem & 5,59 & 0,88 \\
\hline & & Mulher & 5,96 & 0,73 \\
\hline
\end{tabular}

TABELA 3

Análise de variância de três fatores comparando os efeitos da Subfunção, tipo de escola e sexo sobre o QVB

\begin{tabular}{lccccc}
\hline & $G L$ & $S Q$ & $Q M$ & $F$ & $p$ \\
\hline Subfunção & 5 & 378.32 & 75.664 & 889.457 & $<0.001$ \\
Escola & 1 & 29.54 & 29.538 & 347.229 & $<0.001$ \\
Sexo & 1 & 7.27 & 7.266 & 85.416 & 0.004 \\
Subfunção:Escola & 5 & 50.63 & 10.126 & 119.035 & $<0.001$ \\
Subfunção:Sexo & 5 & 24.58 & 4.915 & 57.783 & $<0.001$ \\
Escola:Sexo & 1 & 0.02 & 0.017 & 0.0204 & 0.8863 \\
Subfunção:Escola:Sexo & 5 & 4.19 & 0.838 & 0.9853 & 0.4252 \\
Residuos & 2694 & 2291.73 & 0.851 & & \\
\hline
\end{tabular}

TABELA 4

Resultados das análises de variância comparando cada Subfunção por Sexo e tipo de Escola

\begin{tabular}{lcccc}
\hline \multicolumn{1}{c}{ Subfunção } & & Escola & Sexo & Interação \\
\hline \multirow{2}{*}{ Existência } & $\mathrm{F}$ & 21,92 & 1,336 & 0,518 \\
& $\mathrm{p}$ & $<\mathbf{0 , 0 0 1}$ & 0,248 & 0,472 \\
Experimentação & $\mathrm{F}$ & 4,21 & 3,76 & 1,58 \\
& $\mathrm{p}$ & $\mathbf{0 , 0 4 1}$ & $\mathbf{0 , 0 5 3}$ & 0,289 \\
Interativa & $\mathrm{F}$ & 0,916 & 10,51 & 0,88 \\
& $\mathrm{p}$ & 0,339 & $\mathbf{0 , 0 0 1}$ & 0,348 \\
Normativa & $\mathrm{F}$ & 50,56 & 5,01 & 0,08 \\
& $\mathrm{p}$ & $<\mathbf{0 , 0 0 1}$ & $\mathbf{0 , 0 2 5}$ & 0,777 \\
Realização & $\mathrm{F}$ & 4,49 & 1,35 & 1,53 \\
& $\mathrm{p}$ & $\mathbf{0 , 0 3 4}$ & 0,245 & 0,215 \\
Suprapessoal & $\mathrm{F}$ & 3,18 & 16,02 & 0,24 \\
& $\mathrm{p}$ & $\mathbf{0 , 0 7 4}$ & $<\mathbf{0 , 0 0 1}$ & 0,62 \\
\hline
\end{tabular}

$\mathrm{N}=453$; $\mathrm{F}$ : valor da estatística $\mathrm{F}$ : $\mathrm{p}$ : valor da probabilidade. Em negrito, valores estatisticamente significativos $(\mathrm{p} \leq 0,05)$.

\section{DISCUSSÃO}

O objetivo deste estudo foi avaliar valores em jovens a partir de subfunções valorativa de Gouveia (2013), e possíveis diferenças dessa avaliação quanto a sexo e a inserção de adolescentes em escolas privadas ou públicas da Baixada Santista (SP). Os resultados indicaram o predomínio da subfunção valorativa existência em toda a amostra, não validando o esperado para essa fase do desenvolvimento (adolescência), isto é, o predomínio da subfunção experimentação.

A subfunção valorativa existência, como introduzido, condiz com necessidades elementares, ou seja, com o objetivo do indivíduo de garantir a própria 
existência orgânica individual, tanto em um plano biológico quanto psicológico e de segurança. Essa subfunção expressa necessidades materialistas, ou seja, necessidades de indivíduos com ideias práticas que dão importância à própria sobrevivência e às condições nas quais ela é assegurada. Em termos de orientação (guia de comportamentos), existência é uma subfunção pertencente ao critério central, e difere da subfunção suprapessoal (também pertencente ao critério de orientação central) principalmente pelo fato de que as pessoas que vivem em ambientes de escassez econômica priorizam a primeira subfunção (Gouveia, 2013; Medeiros et al., 2012).

Apesar de não ser seu principal objetivo, o estudo de Medeiros et al. (2012) para verificação da adequação da Teoria Funcionalista dos Valores Humanos no contexto paraibano, apresentou também maior média e menor desvio padrão na subfunção valorativa existência, em uma amostra de 12.706 pessoas.

Traçando um paralelo de nossos resultados e dos resultados encontrados por Medeiros et al. (2012) com o discurso de La Taille e Menin (2009) sobre o processo de transformação de valores ao longo das diferentes épocas, poderíamos considerar como hipótese que valores do critério de orientação central estejam predominando na época atual em centros urbanos brasileiros. Porém, deve ser salientado que a adolescência é um período crítico na vida dos indivíduos, em que há experimentação de valores, papéis sociais e identidades que poderão ou não permanecer na vida adulta (Cavalcante et al., 2008).

A amostra do presente estudo foi constituída por adolescentes estudantes tanto de escolas públicas quanto de privadas. Gouveia (2013) considera a subfunção existência como mais comum em pessoas que vivem em situação de escassez econômica. Embora o recorte da amostra de estudantes de escolas públicas não tenha se caracterizado prioritariamente pelas classes econômicas mais baixas (Tabela 1), os adolescentes de escola pública investigados apresentaram predominância significativa da subfunção existência, quando comparados com os estudantes de escolas privadas.

Em estudos correlacionais entre as subfunções valorativas e diversos aspectos da vida, foi verificada relação entre a subfunção existência e: a intenção de constituir família (Milfont et al., 2006); busca de parceiros ideais com características afetuosas (Gouveia et al., 2010); e interesses convencionais quanto a vocação profissional (Gouveia et al., 2008). Adicionado a isso, outros estudos, também correlacionais, não encontraram relação da subfunção existência com: atitudes preconceituosas (Vasconcelos, Gouveia, Souza Filho, Souza, \& Jesus, 2004) e comportamento antissocial ou delitivo (Formiga \& Gouveia, 2005).

A subfunção valorativa suprapessoal, a segunda subfunção mais presente na amostra, em geral, apresentou-se significativamente predominante em meninas e em escolas públicas. As subfunções suprapessoal e existência formam o critério de orientação central, o qual inclui e é compatível de forma coexistente com os valores pessoais e sociais, servindo a interesses mistos (individuais e coletivos) (Gouveia, 2013). Baseado na ideia de Gouveia (2003) de que valores que visam o individualismo podem influenciar comportamentos aversivos, enquanto valores coletivistas podem contribuir para a diminuição dos mesmos, seria possível pensar que o critério de orientação central estaria relacionado a manifestações comportamentais tanto negativas quanto positivas, no âmbito social. Apesar disso, os estudos correlacionais citados anteriormente mostraram que tanto a subfunção existência, quanto a suprapessoal, ambas pertencentes ao critério de orientação central como um todo, relacionam-se com atitudes de caráter moral e aceitas pela sociedade. Os valores humanos expressos pelos adolescentes estudados podem ser, portanto, reflexo do que é ensinado e vivenciado na escola, família e sociedade no geral, conforme as ideias de Hernandez et al. (2012), colocadas anteriormente.

Em contraste com os resultados do presente estudo, que apontam para a predominância de valores que guiam comportamentos positivos no âmbito social em adolescente, estatísticas oficiais brasileiras sobre criminalidade mostram que, a partir da década de 1970, houve aceleração do crescimento de todas as modalidades delituosas, principalmente em grandes centros urbanos (Adorno, 2002). As teorias de Batson e Thompson (2001) sobre hipocrisia moral e integridade dominada apresentam um possível viés explicativo para o fato. Segundo esses autores, algumas pessoas que têm ideais morais costumam falhar em agir moralmente porque isso lhes implicaria custos pessoais, havendo um limiar variável de pessoa para pessoa, e de acordo com a motivação para agir ou não de forma moral. A partir dessa ideia, Batson e Thompson discutem ainda que pode haver imprecisão em questionários sobre moralidade. Isso aconteceria porque os indivíduos costumam saber os valores prezados pela sociedade e, portanto, pontuar mais em questões sobre tais valores, apesar de muitas vezes não serem realmente guiados por eles em situações reais em que isso lhes implicaria custos pessoais.

Voltando aos resultados deste estudo, a subfunção valorativa experimentação foi significativamente 
predominante em meninos e em escolas privadas. Conforme Gouveia (2013), essa subfunção é bastante encontrada em jovens, e define indivíduos com necessidades idealistas e orientação pessoal, que buscam satisfações de necessidades fisiológicas, não se conformam facilmente com regras sociais e são menos pragmáticos na busca por status ou estabilidade sociais. Os valores dessa subfunção podem contribuir para mudanças na estrutura de organizações sociais. Em estudos prévios com o QVB, a subfunção valorativa experimentação também foi relacionada com atitudes antissociais e delitivas (Formiga \& Gouveia, 2005), busca por parceiros tradicionais e com físico atlético (Gouveia et al., 2010), atitudes favoráveis à tatuagem (Gouveia, Medeiros, Vione, \& Athayde, 2010), vítima da síndrome do burnout (Gouveia Milfont, Fischer, \& Coelho, 2009) e à vocação artística (Gouveia et al., 2008).

O critério de orientação social é composto, segundo Gouveia (2013), pelas subfunções valorativas normativa e interativa, ambas significativamente predominantes nas meninas da amostra. A subfunção normativa diz respeito a pessoas que manifestam comportamentos de obediência a autoridades e preservação de normas culturais, enquanto a interativa define indivíduos que buscam manter relações interpessoais.

Para algumas considerações finais, coloca-se que, pelas características do estudo, os achados não podem almejar generalizações. Os resultados encontrados, em termos de maiores médias de valores encontradas de forma significativa em meninas e em escolas públicas, e maior expressividade da função valorativa existência - despertam interesses de maior compreensão sobre valores presentes em estudantes adolescentes de diferentes inserções escolares.

Com o pressuposto da importância do estudo de valores humanos para intervenções voltadas ao desenvolvimento positivo, serão benvindas novas pesquisas que permitam maior amplitude e diversidade comparativa, além de aprofundamento na investigação de valores na adolescência e juventude presentes numa contemporaneidade marcada pelas novas interações entre as pessoas, as novas tecnologias e o ambiente.

\section{REFERÊNCIAS}

Adorno, S. (2002). Crime e violência na sociedade brasileira contemporânea. Jornal de Psicologia - PSI, 7-8.

Araújo, U. F. (2001). O ambiente Escolar cooperativo e a construção do juízo moral infantil: sete anos de estudo longitudinal. Revista Online Biblioteca Professor Joel Martins, 2(2), 1-12.

Associação Brasileira de Empresas de Pesquisa. (2013). Critério de classificação econômica Brasil. São Paulo: Abep, 2013. Recuperado em 02 jul. 2013, de <www.abep.org>.

Bataglia, P. U. R., Morais, A., \& Lepre, R. M. (2010). A teoria de Kohlberg sobre o desenvolvimento do raciocínio moral e os instrumentos de avaliação de juízo e competência moral em uso no Brasil. Estudos de Psicologia, 15(1), 25-32. http://dx.doi.org/10.1590/s1413-294x2010000100004

Batson, C. D. \& Thompson, E. R. (2001). Why don't moral people act morally? Motivational considerations. Current directions in psychological science, 10(2), 54-57. http://dx.doi.org/10.1111/1467-8721.00114

Carlo, G. \& Koller, S. H. (1998). Desenvolvimento moral pró-social em crianças e adolescentes: conceitos, metodologias e pesquisas no Brasil. Psicologia: teoria e pesquisa, 14(2), 161-172.

Cavalcante, M. B. P. T., Alves, M. D. S., \& Barroso, M. G. T. (2008). Adolescência, álcool e drogas: uma revisão na perspectiva da promoção da saúde. Escola Anna Nery Revista de Enfermagem, 12(3), 555-559. http://dx.doi. org/10.1590/S1414-81452008000300024

Formiga, N. S. \& Gouveia, V. V. (2005). Valores humanos e condutas anti-sociais e delitivas. Psicologia teoria e prática, $7(2), 134-170$.

Freud, S. (2010). O mal-estar na civilização. In (P. C. Souza, Trad.). O mal-estar na civilização, novas conferências introdutórias à psicanálise e outros textos (1930-1936). São Paulo: Companhia das Letras (Obra original publicada em 1930).

Gouveia, V. V. (2003). A natureza motivacional dos valores humanos: evidências acerca de uma nova tipologia. Estudos de Psicologia, 8(3), 431-443. http://dx.doi.org/10.1590/S1413-294X2003000300010

Gouveia, V. V. (2013). Teoria funcionalista dos valores. In V. V. Gouveia (Ed.). Teoria funcionalista dos valores humanos: fundamentos, aplicações e perspectivas (pp. 111-160). São Paulo: Casa do Psicólogo.

Gouveia, V. V., Milfont, T. L., Fischer, R., \& Santos, W. S. (2008). Teoria Funcionalista dos valores humanos. In M. L. M. Teixeira (Org.). Valores Humanos e Gestão: novas perspectivas (pp. 47-80). São Paulo: Senac.

Gouveia, V. V., Meira, M., Gusmão, E. E. S., Souza Filho, M. L., \& Souza, L. E. C. (2008). Valores humanos e interesses vocacionais: um estudo correlacional. Psicologia em Estudo, 13(3), 603-611. http://dx.doi.org/10.1590/S141373722008000300022

Gouveia, V. V., Milfont, T. L., Fischer, R., \& Coelho, J. A. P. M. (2009). Teoria funcionalista dos valores humanos: aplicações para organizações. Revista de Administração Mackenzie, 10(3), 34-59. 
Gouveia, V. V., Fonseca, P. N., Gouveia, R. S. V., Diniz, P. K. C., Cavalcanti, M. F. B., \& Medeiros, E. D. (2010). Correlatos valorativos de atributos desejáveis de um/a parceiro/a Ideal. Psicologia: Reflexão e Crítica, 23(1), 166-175. http://dx.doi.org/10.1590/s0102-79722010000100020

Hernandez, D. H.; Arango, I. M., \& Quintana, M. P. (2012). La formacion de valores de la junventud de nuestros dias. Revista Cubana de Higiene e Epidemiologia, 50(3), 427-437.

Macedo, R. M. S. \& Kublikowski, I. (2009). Valores positivos e desenvolvimento do adolescente: perfil de jovens paulistanos. Psicologia em Estudo, 14(4), 689-698. http://dx.doi.org/10.1590/S1413-73722009000400009

La Taille, Y. \& Menin, M. S. S. (2009). Crise de valores ou valores em crise? Porto Alegre: Artmed.

Medeiros, E. D. (2011). Teoria funcionalista dos valores humanos: testando sua adequação intra e interculturalmente (Tese). Universidade Federal da Paraíba, João Pessoa.

Medeiros, E. D., Gouveia, V. V., Gusmão, E. E. S., Milfont, T. L., Fonseca, P. N., \& Aquino, T. A. A. (2012). Teoria funcionalista dos valores humanos: evidências de sua adequação no contexto paraibano. Rev. Adm. Mackenzie, 13(3), 18-44. http://dx.doi.org/10.1590/S1678-69712012000300003

Milfont, T. L., Gouveia, V. V., Costa, J. B. (2006). Determinantes psicológicos da intenção de constituir família. Psicologia: Reflexão e Crítica, 19(1), 25-33. http://dx.doi.org/10.1590/s0102-79722006000100005

Oliveira, I. C. V. \& Saldanha, A. A. W. (2010). Estudo comparativo sobre a perspectiva de futuro dos estudantes de escolas públicas e privadas. Paideia, 20(45), 47-55. http://dx.doi.org/10.1590/s0103-863x2010000100007

Pratta, E. M. M. \& Santos, M. A. (2007). Família e adolescência: a influência do contexto familiar no desenvolvimento psicológico de seus membros. Psicologia em Estudo, 12(2), 247-256. http://dx.doi.org/10.1590/S141373722007000200005

Razera, J. C. C. (2009). Piaget e os estudos contemporâneos sobre moral: interfaces ainda a discutir. Psico-USF, 14(1), 125-127. http://dx.doi.org/10.1590/S1413-82712009000100013

Rokeach, M. (1981). Crenças, atitudes e valores - uma teoria de organização e mudança. Rio de Janeiro: Interciência.

Salles, L. M. F. (2005). Infância e adolescência na sociedade contemporânea: alguns apontamentos. Estudos de Psicologia, 22(1), 33-41. http://dx.doi.org/10.1590/S0103-166X2005000100005

Santos, V. E., Yonekura, T., Soares, C. B., \& Campos, C. M. S. (2012). Valores sociais: com a palavra a juventude. Acta Paul Enferm, 25(2), 263-269. http://dx.doi.org/10.1590/s0103-21002012000200017

Schwartz, H. S. (2005). Valores humanos básicos: Seu contexto e estrutura intercultural. In A. Tamayo \& J. B. Porto (Org.). Valores e comportamento nas organizações (pp. 21-55). Petrópolis: Vozes.

Souza, L. L. \& Vasconcelos, M. S. (2009). Juízo e ação moral: desafios teóricos em psicologia. Psicologia \& Sociedade, 21(3), 343-352. http://dx.doi.org/10.1590/s0102-71822009000300007

Traverso-Yépez, M. A., \& Pinheiro, V. S. (2002). Adolescência, saúde e contexto social: esclarecendo práticas. Psicologia \& Sociedade, 14(2), 133-147. http://dx.doi.org/10.1590/S0102-71822002000200007

Vasconcelos, T. C., Gouveia, V. V., Souza Filho, M. L., Souza, D. M. F., \& Jesus, G. R. (2004). Preconceito e intenção em manter contato social: evidências acerca dos valores humanos. Psico-USF, 9(2), 147-154.

Vasconcelos, M. S., Arantes, V. M., Souza, L. L., Trevisol, M. T. C., \& Belloto, M. E. (2010). Juízos e Valores Morais: a perspectiva de investigação dos modelos organizadores do pensamento. Paidéia, 20(46), 207-217. http://dx.doi. org/10.1590/s0103-863x2010000200008

Autores:

PRISCILla BRANDi GOMES GODOY - Graduação em Psicologia, Universidade Federal de São Paulo (UNIFESP-BS).

NANCY RAmacciotti OliveIRA-MonteIRo - Doutorado e Pós-doutorado, Universidade Federal de São Paulo (UNIFESP-BS).

Endereço para correspondência:

Nancy Ramacciotti de Oliveira-Monteiro

Av. Washington Luis, 553, ap. 51

CEP 11055-001 Santos, SP, Brasil

E-mail: nancy.unifesp@gmail.com

Recebido em: 18.11 .14

Aceito em: 06.07.15 